\title{
BENIGN CONGENITAL MYOPATHY WITH MYASTHENIC FEATURES⿰
}

\author{
BY \\ *JOHN N. WALTON, †NORMAN GESCHWIND, and $\ddagger$ J. A. SIMPSON \\ From the Neurological Research Unit and the Biochemical Department of the Institute of Neurology, \\ the National Hospital, Queen Square, London
}

It has been increasingly apparent in recent years that in addition to cases which fall into recognizable categories of muscle disease, a number of less common disorders occur from time to time which do not correspond to the accepted descriptions. Some of these appear to be metabolic in origin and can be elucidated, at least in part, by modern methods of investigation (McArdle, 1951) while others seem to fall into a borderland of either myopathy or myasthenia gravis. A case of the latter type is described and discussed below.

\section{Case History}

R. M. (N. H. case 4838), a female telephonist, was born in 1919; her mother was well during pregnancy, labour was normal, and the baby thrived well during the neonatal period. She seemed normally active and lively and sat up at 7 months; at 9 months she tipped over her pram by jumping vigorously and sustained a cut chin but no other injury. Shortly after this episode her mother noticed that the limbs and body tended to flop limply when she was lifted and the head lolled as if she were totally unable to support it. The limbs were unusually flexible, like those of a rag doll, and she lay in her pram almost immobile, without kicking her legs or waving her arms. Nevertheless, at the age of a year she was able to crawl a short distance when put on the floor; her crawling improved steadily, although her limbs remained rather loose and "floppy". However, this was her only means of locomotion until she reached the age of 5 years, when she began to pull herself up with her arms and to walk around the furniture. When she was $5 \frac{1}{2}$ years old she was able to walk a few paces unaided and the limbs, though somewhat weak, were not so loose. The patient's mother suggested that at this age she was very little stronger but had learned to overcome her weakness. At the age of 7 she was able to go to a school for disabled children and could walk about 20 yards, but would then have to rest for about a minute in order to regain her strength. She always tended to tire throughout the day and was much

*King's College (Newcastle) Travelling Fellow in Medicine; aided by a grant from the Muscular Dystrophy Associations of America, Inc. + Research Fellow, National Institutes of Health, U.S. Public Health Service, 1953-55.

¥Clinical Research Fellow of the Medical Research Council. weaker in the evening than on waking. She had particula $\frac{\bar{O}}{\bar{c}}$ difficulty in climbing stairs or in rising from a low chait and showed a considerable tendency to trip and fall, after which she would find it difficult to get up again Apart from her muscular disability the patient developed normally; the menarche occurred at 13 years and she had menstruated normally since.

As the patient grew older she was gradually able to extend her activities, although her muscular weakness was virtually unchanged. She attempted numerous 0 occupations and finally worked (from 1948) for twoyears as a telephonist, but was compelled to give up this post because of her muscular disability; since 1950 s⿵⺆⿻二丨冂 had helped her mother in the home. The patient hogd two sisters, one older and one younger than hers of, 0 both of whom were well, and there was no history muscular disease in the family.

The patient was first admitted to the National Hospitale in 1941 under the care of Dr. E. A. Carmichael, whenc generalized muscular hypotonia of moderate degree $\mathrm{m}^{\mathrm{N}} \stackrel{\rho}{\rightarrow}$ diffuse atrophy of proximal limb muscles were discovere्d. $\overrightarrow{0}$ She showed an accentuated lumbar lordosis and tendêd to waddle when she walked. There was also bilateral ptosis and weakness of the upper facial musculature. A diagnosis of atypical amyotonia congenita was made. She was readmitted on several occasions during the ensuing years, when her symptoms and physical signs were virtually unchanged. In 1944 she was seen by Dr. $\mathbb{Q}$ Gordon Holmes, who suggested that she was suffering from an unidentified defect of muscle metabolism. In음 1948 Sir Charles Symonds could demonstrate no myasthenic tiring of the eyelids, although there was pathological fatiguability of the deltoids; he agreed that the patient was suffering from an unusual metabolic disorder of muscle. On at least three occasions the effect of an intramuscular injection of $1.5 \mathrm{mg}$. prostigmine was tested. Each time the drug made the patient feel 3 "queer" and dizzy, but nevertheless it produced some subjective improvement in muscular power, though there $ᄋ$ was little objective change. Twice the improvement in strength appeared to persist for two or three days after 윽 the injection and the drug was given by mouth in a dosage $D$ of up to $90 \mathrm{mg}$. daily. On each occasion there was a marked subjective improvement which, however, passed off after between one and two weeks and the treatment $\mathscr{O}$ was discontinued. A similar improvement appeared to $\mathrm{N}$ follow ephedrine, gr. $\frac{1}{2}$, three times daily; the effect of $\mathrm{N}$ 


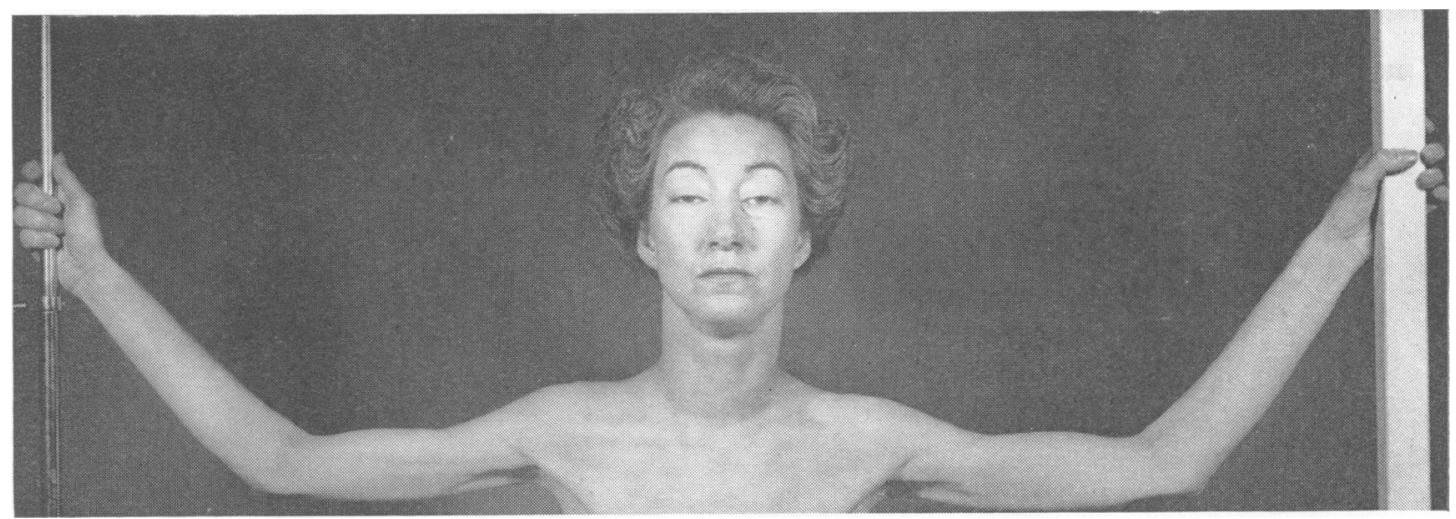

Fig. 1.-The bilateral ptosis and moderate atrophy of the shoulder girdle and arm muscles (particularly on the right side) are seen.

this drug was, in the patient's view, sustained, and she had been taking it continuously for several years. In 1952 the patient was admitted to the Clinical Research Unit at Guy's Hospital and was investigated by Dr. B. McArdle; the results of these studies are given below. At that time she seemed to show doubtful improvement on treatment with oral potassium (dosage $1 \mathrm{~g}$. $\mathrm{KCl}$ t.d.s.) and had continued to take this remedy, as well as ephedrine, until she returned to the National Hospital in 1955. Assessment of therapeutic results in this patient was always difficult as she was a suggestible, nervous individual, who suffered numerous episodes of emotional instability, exaggerated by periods of conflict with her mother.

On readmission under the care of Dr. Carmichael on May 6, 1955, the patient's symptoms were virtually unchanged from those she had expressed on her previous admissions, save for the fact that she had experienced occasional dysphagia when tired. However, she was still able to do housework and to walk considerable distances (with many rest periods). She felt that the muscles of her legs seemed to "let her down" less often than they had done some years before, but there had been no striking change in the condition of the limbs for many years.

On examination (Fig. 1) the patient was thin and slightly built and walked with a distinct waddle and with a considerable increase in the lumbar lordosis. There was bilateral ptosis, with impaired ocular movement upwards, but not laterally or downwards; the ocular axes were parallel throughout and there was no diplopia. Both orbiculares oculi were strikingly weak, but the lower facial muscles, masseters, and temporales were strong. Palatal and pharyngeal movements were normal and the tongue showed no atrophy or fasciculation. The patient had a curiously long " swan-like" neck, but the sternomastoids were large and powerful as were the posterior cervical muscles; because of the ptosis she tended to hold her head backwards. There was undoubtedly atrophy of the sacrospinalis and other posterior spinal muscles, but those of the abdominal wall were good. The limbs were generally thin, particularly proximally, and there seemed to be a general moderate atrophy, with considerable weakness, of all girdle and proximal muscles in the upper and lower limbs. The extensors of the wrist and fingers were also weak; the finger flexors were stronger but, nevertheless, considerably weaker than would have been expected in a normal individual of the patient's age. In the lower limbs the anterior tibial and peroneal groups showed the same atrophy and weakness as the proximal muscles, although the calf muscles were more powerful. All deep tendon reflexes were present, though depressed, and direct muscle excitability was normal; the abdominal reflexes were brisk, the plantar responses flexor. The secondary sexual characteristics were normally developed and there was no abnormality to be detected on examination of the chest, abdomen, and cardiovascular system.

Electrodiagnosis.- In 1948, an intensity-duration curve from the right deltoid was normal; Dr. W. A. Cobb recorded an electromyogram from the same muscle, using a concentric needle electrode. He reported that there was no spontaneous activity and on voluntary contraction the motor unit action potentials were normal in amplitude and duration. In June, 1948, Dr. P. Merton found no decrement in the amplitude of a muscle action potential recorded with a surface electrode on the hypothenar eminence, on supra-maximal stimulation of the ulnar nerve at 3 per second.

Muscle Biopsy.-A specimen of muscle was removed from the right deltoid in $\mathbf{1 9 5 0}$. There was no increase in perimysial connective tissue nor was there any accumulation of fat between the fibres. Some of the muscle fibres were slightly enlarged, measuring $85 \mu$ in diameter, while very occasional atrophic fibres were seen. In a few fibres sarcolemmal nuclei had migrated into the substance of the fibre and one or two short chains of nuclei, subsarcolemmal in position, were seen. No segmental necrosis of fibres was evident and there was no cellular infiltration or evidence of muscle fibre regeneration. A number of nerve filaments were present in the section and appeared to be normal; two muscle spindles of normal appearance were also observed. Hence the histological changes were minimal. Although perhaps compatible with a mild myopathic disorder they were 
much less than would have been expected considering the length of history and the comparative severity of the patient's weakness.

Dr. J. N. Cumings reported that the potassium content of the muscle was $1 \cdot 1 \mathrm{~g} . \%$ by dry weight, a normal figure.

Metabolic Studies.-Studies carried out in June, 1948, by Dr. J. N. Cumings yielded the following results:-

\section{CREATINE AND CREATININE EXCRETION}

\begin{tabular}{c|c|c|c|c}
\hline Day & $\begin{array}{c}\text { Urinary } \\
\text { Volume } \\
\text { (ml.) }\end{array}$ & $\begin{array}{c}\text { Creatinine } \\
\text { (g.) }\end{array}$ & $\begin{array}{c}\text { Creatine } \\
\text { (g.) }\end{array}$ & $\begin{array}{c}\text { Inorganic } \\
\text { Phosphate } \\
(\mathrm{g} .)\end{array}$ \\
\hline 1 & 900 & 0.73 & 0.18 & 0.51 \\
2 & 820 & 0.84 & 0.27 & 0.53 \\
3 & 940 & 0.86 & 0.12 & 0.41 \\
4 & 763 & 0.79 & 0.16 & 0.40 \\
5 & 570 & 0.75 & 0.04 & 0.51 \\
6 & 940 & 0.87 & 0.08 & 0.56 \\
\hline
\end{tabular}

Ephedrine medication and all other medicinal treatment was discontinued from the third day of this test; a creatine tolerance test was performed on the fourth day and gave results as follows :-

Creatine Tolerance Test.-Urinary and blood estimations were carried out at the stated times before and after the oral ingestion of $1 \mathrm{~g}$. of creatine.

RESULTS IN URINE

\begin{tabular}{|c|c|c|c|c|}
\hline Time & $\underset{\text { (ml.) }}{\text { Volume }}$ & $\begin{array}{c}\text { Creatinine } \\
\text { (g.) }\end{array}$ & $\begin{array}{c}\text { Creatine } \\
\text { (g.) }\end{array}$ & $\begin{array}{c}\text { Inorganic } \\
\text { Phosphate } \\
\text { (g.) }\end{array}$ \\
\hline $\begin{array}{l}\text { Fasting } \\
1 \text { hour } \\
2 \frac{1}{2} \text { hours }\end{array}$ & $\begin{array}{r}35 \\
57 \\
121\end{array}$ & $\begin{array}{l}0.07 \\
0.05 \\
0.10\end{array}$ & $\begin{array}{l}0.01 \\
0.05 \\
0.04\end{array}$ & $\begin{array}{l}0.03 \\
0.02 \\
0.03\end{array}$ \\
\hline
\end{tabular}

RESULTS IN BLOOD

\begin{tabular}{|c|c|c|c|c|}
\hline Time & $\underset{(\mathrm{mg} . \%)}{\text { Creatinine }}$ & $\begin{array}{l}\text { Creatine } \\
\text { (mg. \%) }\end{array}$ & $\begin{array}{c}\text { Inorganic } \\
\text { Phosphate } \\
\text { (mg. \%) }\end{array}$ & $\begin{array}{c}\text { Potassium } \\
(\mathrm{mg} . \%)\end{array}$ \\
\hline $\begin{array}{l}\text { Fasting } \\
1 \text { hour } \\
2 \frac{1}{2} \text { hours }\end{array}$ & $\begin{array}{l}1 \cdot 0 \\
1 \cdot 12 \\
1 \cdot 25\end{array}$ & $\begin{array}{l}0.38 \\
1.63 \\
0.87\end{array}$ & $\begin{array}{l}4 \cdot 3 \\
4 \cdot 7 \\
4 \cdot 7\end{array}$ & $\begin{array}{l}19 \cdot 4 \\
20 \cdot 0 \\
22 \cdot 5\end{array}$ \\
\hline
\end{tabular}

Response to Insulin and Glucose.-The patient was given $100 \mathrm{~g}$. glucose by mouth and 25 units of insulin subcutaneously. Before the experiment was begun the serum potassium level was $20.0 \mathrm{mg} . / 100 \mathrm{ml}$., the serum inorganic phosphate level $4.5 \mathrm{mg}$. $/ 100 \mathrm{ml}$., and the blood sugar level $100 \mathrm{mg} . / 100 \mathrm{ml}$. Thirty minutes after the injection, the serum potassium level was $18 \cdot 3 \mathrm{mg} . / 100 \mathrm{ml}$., the inorganic phosphate level was unchanged, and the blood sugar level was $168 \mathrm{mg}$. $/ 100 \mathrm{ml}$.

Dr. Cumings remarked that the urinary creatine was low and almost absent when the patient was taking no drugs, while the creatine tolerance and the potassium response to insulin and glucose were all normal.

Metabolic Activity of Forearm Muscles.-In January, 1952, the following studies were carried out by Dr. B. McArdle in the Clinical Research Unit at Guy's Hospital, London. The patient had received no drugs for about a week before the test. Blood was taken from the left antecubital vein before the test and again following the release of an occluding cuff after a period of ischaemic work by the forearm muscles. The work consisted in raising and lowering (56 pulls) a $5 \mathrm{~kg}$. weight by meansD of a gripping movement on an ergometer. A wrist cuff inflated to $200 \mathrm{~mm}$. $\mathrm{Hg}$ ensured that blood taken from the antecubital vein came only from the forearm muscles The results of this test were as follows :-

\begin{tabular}{|c|c|c|c|c|c|c|}
\hline Time & $\begin{array}{c}\text { Blood } \\
\text { Pyru- } \\
\text { vate } \\
\text { (mg. \%) }\end{array}$ & $\begin{array}{c}\text { Blood } \\
\text { Lac- } \\
\text { tate } \\
\text { (mg. } \%)\end{array}$ & $\begin{array}{c}\text { Serum } \\
\text { Potas- } \\
\text { sium } \\
(\mathrm{mg} . \%)\end{array}$ & $\begin{array}{l}\text { Serum } \\
\text { Sodium } \\
\text { (mg. \%) }\end{array}$ & $\begin{array}{c}\text { Serum } \\
\text { Mag- } \\
\text { nesium } \\
\text { (mg. \%) }\end{array}$ & $\begin{array}{c}\text { Serum } \Omega \\
\text { Inorganie } \\
\text { Phos- } \\
\text { phate } \\
(\mathrm{mg} . \%) .\end{array}$ \\
\hline Before & 0.63 & $6 \cdot 0$ & $15 \cdot 2$ & 325 & $2 \cdot 23$ & $3.57 \overline{\bar{\sigma}}$ \\
\hline lease of cuff & $1 \cdot 26$ & $31 \cdot 3$ & $16 \cdot 4$ & 340 & $2 \cdot 50$ & 3.67 \\
\hline $\begin{array}{l}2 \text { min. after re- } \\
\text { lease of cuff }\end{array}$ & 0.91 & $29 \cdot 4$ & $15 \cdot 6$ & - & - & - \\
\hline 6 min. after re- & $1 \cdot 13$ & $24 \cdot 2$ & $14 \cdot 8$ & 328 & - & $3 \cdot 28 \frac{\mathrm{s}}{\frac{\mathrm{D}}{\mathrm{D}}}$ \\
\hline lease of cuff & 1.01 & $16 \cdot 3$ & $14 \cdot 7$ & 330 & 一 & \\
\hline lease of cuff & 0.86 & $12 \cdot 7$ & $14 \cdot 5$ & 329 & - & $\overline{3 \cdot 18}$ \\
\hline
\end{tabular}

Dr. McArdle remarked that all of these results were within normal limits.

Other Investigations.-Haemoglobin was 100 \% $(14.8$ g. $/ 100 \mathrm{ml}$.); W. B. C. $4,000 /$ c.mm. (63\% polymoro phonuclears, $31 \%$ lymphocytes).

The E. S. R. was $8 \mathrm{~mm}$. in one hour (Westergren) The Wassermann and Kahn reactions were negative.

The serum protein-bound iodine was $3 \gamma \%$. कीसे total serum proteins were $7.9 \mathrm{~g} . / 100 \mathrm{ml}$. (albumin $\$ .4$ globulin 3.5).

A radiograph of the chest showed a slight docsal scoliosis, convex to the right. The lung fields and hear were normal and the thymus did not appear to begne larged. An electrocardiogram was normal, and a bsaf metabolic rate was minus $11 \%$. The urinary $17-\mathrm{ke}$ steroid excretion was $4.9 \mathrm{mg}$. in 24 hours.

\section{Discussion and Experiments}

It was clear from the information recorded the this patient fitted no clearly recognizable form of muscle disease as previously described. The non progressive nature of the disease and the diffus 8 rather than selective distribution of muscula wasting and weakness made it apparent that sh was not suffering from any of the common categories of muscular dystrophy. Furthermore, the pathos logical changes in the muscle were far less than would: have been expected in a long-standing muscula dystrophy or polymyositis. She showed man\% characteristics reminiscent of the benign congenita myopathy or myopathic form of amyotonig congenita as described by Batten (1910) and b Aldren Turner (1940, 1949). Because of the generat reduction in size of the skeletal muscles, the resemblance to Krabbe's (1946) "congenitad universal muscular hypoplasia" was even morestriking, since in Turner's cases the muscula wasting and weakness affected selectively the proximal muscles of the limbs and the face was noㅇ 
involved. Despite these discrepancies, the results of a recent follow-up of cases of amyotonia congenita by one of us (Walton, 1956) have suggested that the disorders described by Krabbe and Turner may be the same. However, in this case there were additional unusual features: the variability of her weakness, the fatiguability, which had been a consistent feature, and the apparent response to ephedrine, suggested that there might be some defect in neuromuscular transmission akin to that seen in myasthenia gravis. It was evident that the patient was not suffering from the latter disease, in view of the diffuse muscular wasting and the failure to show a sustained response to prostigmine therapy. Rowland (1955) has recently described a number of patients who appeared to be suffering from myasthenia gravis but who showed either a very variable response to prostigmine or none at all. However, from his descriptions it seems likely that some of his cases were examples of polymyositis, a condition which may show temporary improvement with this drug (Eaton, 1954). It is clear from the clinical and pathological findings that our case was not suffering from polymyositis. An alternative possibility seemed to be that she was suffering from an unidentified disorder of muscle metabolism, although Dr. McArdle's results indicated that there was no serious defect in carbohydrate breakdown and utilization in the muscle.

In view of the apparent improvement which the patient had shown on potassium therapy it was decided to investigate the effect upon her muscular power of alterations in the serum potassium level. It was recognized that her symptoms were not like those of familial periodic paralysis, nor were they characteristic of those noted in chronic potassium deficiency (as in potassium-losing nephritis). It was also appreciated that the serum potassium level does not necessarily give a faithful indication of the intramuscular concentration of this ion. Nevertheless, since potassium is recognized to be one of the most freely diffusible ions, it was felt that if the patient's condition were due to a deficiency of intramuscular potassium, she would become significantly weaker if the serum potassium level were lowered. Another possibility seemed to be that she might have some anomaly whereby her muscles required a higher than normal concentration of potassium in order to function properly. In this case, too, a fall in extracellular potassium would increase her weakness.

It was also decided to repeat the electromyogram and to study the effects upon the muscle action potential of repetitive nerve stimulation, first under normal conditions and secondly after increasing doses of intravenous decamethonium iodide. Harvey and Masland (1941) found that in patients with myasthenia gravis, if the muscle action potential was recorded from the skin overlying a weak muscle during repetitive supramaximal stimulation of its nerve of supply at a rate of 3 per second, the potential often showed a rapid decrease in amplitude. This was suggested as a diagnostic test, and it has been conventional to take the recording from the hypothenar eminence during stimulation of the ulnar nerve at the elbow. If this muscle group is not clinically affected, however, another must be chosen. Recently, Churchill-Davidson and Richardson (1952) have shown that in the normal individual an intravenous injection of $2 \mathrm{mg}$. of decamethonium iodide will give a significant fall in amplitude of the motor unit potential recorded from the hypothenar eminence during stimulation of the ulnar nerve at a frequency of 10 per second. Patients with myasthenia gravis, however, in whom the hypothenar muscles were not weakened by the disease, were remarkably resistant to this drug and could often take $3 \mathrm{mg}$. or more without a significant decrement in the action potential.

Clearly it also seemed important in this patient to assess, under the conditions of a controlled experiment, the effect of ephedrine, prostigmine, tensilon, and potassium upon the muscular weakness. It was decided in addition to study the effects of intravenous caffeine and of calcium, in view of the direct stimulant effect which these substances appear to have upon the muscle fibre.

Before carrying out these experiments all treatment was stopped and the patient's muscular power was assessed three times daily by one of us, at 9.30 a.m., 1 p.m., and 5 p.m., in order to see whether there was any significant variation depending upon the time of day. The power of individual muscle groups was assessed clinically and strength of grip was measured with a spring dynamometer, the value recorded being taken as the average of three maximal grips with each of the two hands. It was discovered that the latter test gave a satisfactory indication of general muscular power. Another useful test was to measure the time for which both arms could be held out horizontally in front of the body with the patient sitting in bed; the end-point was taken at the time when one hand touched the bed-clothes. Using these methods it was found that after five days in hospital, with approximately the same amount of activity carried out each day, consistent values for strength of grip and for holding out the arms were obtained from day to day. Each day there was a consistent slight decrease in these readings as the day advanced; for this reason it 
was decided to carry out all experiments at approximately the same time in the mornings. All chemical estimations were carried out by one of us (N. G.) using a standard technique. The assessments of muscular power were made by J. N. W. and electrodiagnostic tests were carried out by J. A. S.

Experiment I: Lowering of Serum Potassium Level.On May 20, 1955, the patient was starved and $5 \mathrm{ml}$. of blood was taken from the right antecubital vein at 9 a.m.; the serum potassium level, as estimated with a flame photometer, was $4.4 \mathrm{mEq}$./litre $(17.2 \mathrm{mg} . / 100 \mathrm{ml}$.). At $9.5 \mathrm{a} . \mathrm{m}$. the patient was given $150 \mathrm{~g}$. glucose orally and at 9.25 a.m. 25 units of insulin were given subcutaneously. At 10 a.m. muscular power was unaltered, but the serum potassium level was $4.1 \mathrm{mEq}$./litre $(16.0 \mathrm{mg} . / 100 \mathrm{ml}$.). Hence the fall in serum potassium level produced by this technique was inadequate.

On May 23, 1955, after a large breakfast, the serum potassium level was estimated at $9.10 \mathrm{a} . \mathrm{m}$. to be $4.0 \mathrm{mEq}$./litre $(15.6 \mathrm{mg} . / 100 \mathrm{ml}$.). At $9.20 \mathrm{a} . \mathrm{m}$., and again at $9.35 \mathrm{a} . \mathrm{m}$. and $9.50 \mathrm{a} . \mathrm{m}$. the patient was given $15 \mathrm{~g}$. sodium bicarbonate in 2 oz. water. At 10.30 a.m. the patient felt somewhat tired and nauseated but there was no objective change in muscle power. At $1.15 \mathrm{p} . \mathrm{m}$. the serum potassium level was $3.12 \mathrm{mEq}$./litre $(12.2 \mathrm{mg} . / 100 \mathrm{ml}$.) and $1 \mathrm{ml}$. of 1 in 1,000 adrenaline was administered subcutaneously. At 2 p.m. the serum potassium level had fallen to $3.0 \mathrm{mEq}$./litre $(11.7 \mathrm{mg}$./ $100 \mathrm{ml}$.) but there was still no significant change in muscular power. This technique for lowering the serum potassium level will be reported in detail by one of us (N. G.) in a subsequent communication.

Experiment II: Electromyography and Effect of Intravenous Tensilon and Ephedrine.-On May 24, 1955, the electromyogram from the right deltoid muscle was recorded at 9.30 a.m., using a concentric needle electrode. There was no spontaneous activity; on voluntary contraction the interference pattern was sustained but contained an undoubted excess of polyphasic and short-duration potentials. After sustained abduction of the arm for 90 seconds, with the needle in situ, the proportion of shortduration and polyphasic potentials showed a significant increase. After assessment of voluntary power, $20 \mathrm{mg}$. " tensilon" was injected intravenously at 10 a.m. The patient immediately felt faint and dizzy and there was no increase in voluntary power, while the electromyogram was unchanged. At 10.50 a.m. ephedrine hydrochloride, gr. $\frac{1}{2}$, was given intravenously; the patient immediately felt stronger, and voluntary power, as assessed

Fig. 2.-Effect of decamethonium on the action potential of abductor digiti minimi during supramaximal ulnar nerve stimulation in R.M. (upper curve) and in a control subject (lower curve). with the dynamometer and by holding out the arms increased to a level higher than any recorded since admission to hospital. The electromyogram now showed fewer polyphasic and short-duration potentials. The patient was unaware of the constitution of any of the injections she received.

Experiment III: Supramaximal Stimulation of Ulnat Nerve before and after Injection of Decamethoniums Iodide.-On June 4, 1955, a surface electrode waș. applied to the left hypothenar eminence (with the indifferent electrode on the fifth finger), and at 10 a.m. recording of the action potential produced by supras? maximal stimulation of the left ulnar nerve at the elbow was begun. With a stimulation frequency of 2 per seconf there was no significant decrease in amplitude of the. motor unit potential over a 10 -minute period. Stimula tion was then discontinued but was restarted at 10.20 a.m? At 10.38 a.m. $1 \mathrm{mg}$. decamethonium iodide was injecteकृ over a two-minute period. Immediately the patient feltfaint and dizzy (as after " tensilon "); her ptosis increased considerably and she developed diplopia, but the action $\omega$ potential of the hypothenar muscles was unchangedo At 10.44 a.m. and at 10.49 a.m. two further injections each of $0.5 \mathrm{mg}$., were given; the patient felt subjectivel weaker but there was no change in the action potentiali A further injection of $0.5 \mathrm{mg}$. was given at $10.54 \mathrm{a} \cdot \mathrm{m}_{\dot{\omega}}$ (total $2.5 \mathrm{mg}$.); at 10.59 the action potential showed $13 \%$ decrease in amplitude; the patient felt weaker, apprehensive, and refused to have further injectionso The original amplitude of the action potential was restoged by $11.25 \mathrm{a} . \mathrm{m}$. With this dose of decamethonium, the action potential of a normal subject would decrease ins amplitude by more than $50 \%$. The results of experiment are recorded graphically in Fig. 2, using he same ordinates as those utilized by Churchill-Davidsonic and Richardson (1952).

Experiment IV: Therapeutic Trials.-Five substances

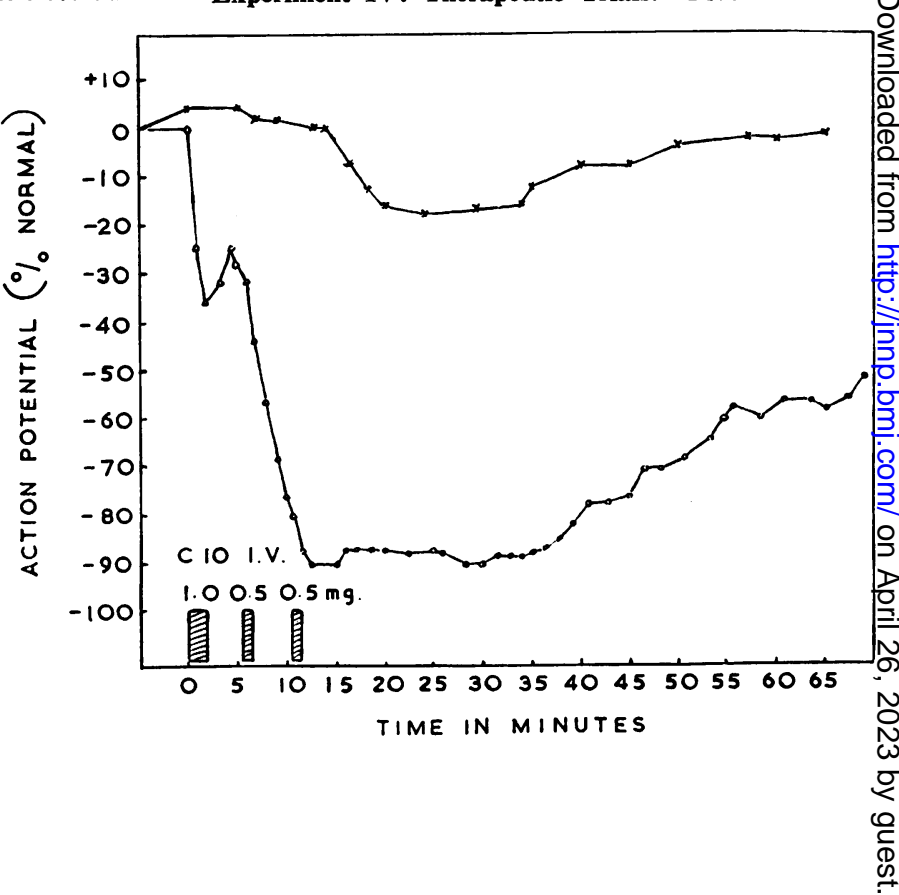


were used, namely, ephedrine, calcium, potassium, caffeine, and prostigmine.

Ephedrine.-For a period of seven days from May 25, 1955 , the patient was given tablets four times daily; for a part of this time the tablets were ephedrine hydrochloride (gr. $\frac{1}{2}$ ), and for the remainder nicotinamide $25 \mathrm{mg}$. (which looked identical). This trial was designed by J. A. S. so that neither the observer testing muscular power (J. N. W.), the patient, nor the ward nurses were aware which tablet was being given at any one time, nor when the treatment was changed. At the end of this period it was clear that during the three-day period of treatment with ephedrine the patient was both subjectively and objectively stronger than when she was receiving nicotinamide.

Calcium.-On successive days the patient received an intravenous infusion of $500 \mathrm{ml}$. of fluid over a two-hour period. One of these infusions consisted of $500 \mathrm{mg}$. of calcium (as the gluconate) in normal saline while the other was saline alone. The observer concerned with the measurement of the patient's muscular power was not aware which infusion was being administered. After each infusion the patient claimed to be considerably stronger and showed a moderate increase in power as recorded dynamometrically and by holding the arms outstretched.

Potassium.-Over a seven-day period, from June 5, 1955 , the patient was given four times a day $1 \mathrm{oz}$. of an orange-flavoured preparation. For a part of this time the preparation contained $2 \mathrm{~g}$. potassium citrate in each ounce and for the remainder sodium citrate. As with the trial of ephedrine neither the patient nor the observer was aware which remedy was being given at any one time nor when the change-over occurred. Throughout this period the patient's condition remained unchanged; neither substance produced a significant change in muscular power.

Caffeine.-On June 12, 1955, the patient received three intravenous injections of comparable volume and appearance at intervals of one hour. One was caffeine sodium benzoate, $0.5 \mathrm{~g}$., another ephedrine hydrochloride, gr. $\frac{1}{2}$, and the other sterile saline. The injections were given by J. A. S. and neither the patient nor the clinical examiner (J. N. W.) was aware which injection was being given. It was discovered that the injection of saline had no effect, but both the ephedrine and the caffeine produced a distinct subjective and objective improvement in muscular strength of comparable degree.

Prostigmine.-On June 13, 1955, it was decided to study the effects of long-term oral prostigmine therapy, despite the fact that this treatment had proved ineffective in the past. Accordingly therapy with $15 \mathrm{mg}$. tablets of prostigmine four times daily was instituted, but was changed, at a time unknown to the patient and observer, to an inert tablet of identical appearance. This trial was continued over a five-day period. There was no doubt that both subjectively and objectively the patient was considerably stronger while on prostigmine. Indeed, she recorded higher dynamometer readings and was able to hold out her arms longer than at any time since her admission to hospital. During the next five days prostigmine therapy was alternated with pyridostigmine in equivalent dosage, but there was little difference in the effect of the two remedies, although overall improvement was maintained.

Subsequent Progress.-As a result of the findings in the experiments outlined above it was decided to give the patient combined treatment with prostigmine, one tablet of $15 \mathrm{mg}$., four times daily, and ephedrine, one tablet of gr. $\frac{1}{2}$, also four times a day. For three days the improvement in the patient's strength was sustained: she moved about the ward more easily, could lift objects of considerable weight, and climbed three flights of stairs relatively briskly. Unfortunately she then developed follicular tonsillitis with a high fever and was compelled to take to her bed. This infection resolved within a few days but left the patient depressed, tearful and weak, though no weaker than she had been on admission. She asked to be discharged, feeling that she would pick up more quickly at home; she therefore left hospital, taking both ephedrine and prostigmine, on June 23, 1955. On discharge, physical examination revealed no significant change from her state on admission.

The patient was readmitted to hospital on August 9, 1955. After returning home she had improved quickly and soon felt that her strength had returned to what it was after beginning combined prostigmine and ephedrine therapy in hospital. This improvement continued for three weeks but then she began to feel unaccountably weaker. Although she had experienced some fluctuation in her muscular strength as a result of emotional disturbances, the present deterioration was quite different, being steadily progressive. In addition, she became short of breath and could no longer lie down in bed at night, or walk more than a few paces because of dyspnoea. On examination on admission the patient was unable to walk more than a few paces with considerable effort and she was quite unable to negotiate stairs. Her resting pulse rate was 120 per minute, but the heart and chest showed no abnormality on examination. She was severely breathless, with very poor abdominal and thoracic movement and striking activity of the accessory muscles of respiration, including the sternomastoids and scaleni. Her ptosis and facial weakness had not increased since her previous admission but her strength of grip was strikingly weak and she was quite unable to lift her arms from the bed. Her vital capacity could not be measured as she said she was unable to blow into the machine. An electrocardiogram was normal but for the tachycardia. Although an accurate assessment of her physical state was made difficult by emotional factors, there was no doubt that she showed persistent tachycardia and severe weakness of limb, trunk, and respiratory muscles, like that seen in severe myasthenia gravis. Intravenous tensilon and intramuscular prostigmine therapy produced no improvement in her condition; indeed, she insisted that these remedies made her worse. After each, some muscular fasciculation was seen but there were no abdominal symptoms. Accordingly, all therapy was 
discontinued and over the next two weeks there was a gradual improvement in her respiration and in the power of the limbs; her pulse rate returned to 80 per minute. The patient was finally discharged from hospital on September 16, 1955, receiving only ephedrine gr. $\frac{1}{2}$ four times daily. Her condition was virtually the same as when she was first admitted in May, 1955.

\section{Conclusions}

There seems to be little doubt whatever that this patient was suffering from a relatively benign, probably congenital, non-progressive myopathy, showing certain features reminiscent of myasthenia gravis. Dr. McArdle's investigations revealed no apparent defect in carbohydrate metabolism, while we were unable to produce any evidence to indicate that alterations in serum potassium affected her muscular condition. Save for the " myasthenic" features, her condition corresponds closely to the " benign congenital myopathy" or myopathic form of amyotonia congenita described by Batten (1910) and Aldren Turner (1940, 1949). However, Turner did not describe any fatiguability or apparent response to ephedrine or prostigmine therapy in his cases, nor were these features seen in the other cases of this type which were reviewed recently by one of us (Walton, 1956). On the other hand, it is evident that this patient was not suffering from true myasthenia gravis, in view of the failure to respond to tensilon, as well as the atypical clinical picture. Nevertheless, it must be admitted that she showed a considerable resistance to decamethonium iodide, while the sustained improvement on ephedrine therapy and the temporary response to prostigmine were suggestive of the latter disease. The apparent increase in strength following an injection of caffeine sodium benzoate was of doubtful significance.

Of great interest was the striking increase in weakness, particularly of the respiratory muscles, after prostigmine therapy had been in progress for some weeks. The associated tachycardia was suggestive of vagal inhibition but it is difficult to see how moderate dosage of prostigmine, which would be expected to give a bradycardia, could produce this effect. It seems most probable that the weakness could be attributed to this drug, despite the absence of other side-effects, and that the temporary improvement, perhaps due to its anti-cholinesterase effect, was subsequently overcome by a persistent depolarizing effect which appeared to be cumulative. It is well recognized that even patients with myasthenia gravis may become weak as a result of excessive dosage of this drug (Rowland, Korengold, Jaffe, Berg, and Shy, 1955), but the dosage administered to our patient was only $60 \mathrm{mg}$. daily which could not be expected to produce such an effect in an individual with true myasthenia. It is also difficult to understand the action of ephedrine in this case Unlike adrenaline, this drug does not cause glycogef breakdown, hyperglycaemia, or a fall in the serum potassium level. We may ask whether its effect i⿺ unrelated to the energy metabolism of muscle ando whether it may have a direct effect upon the muscle membrane or perhaps at the motor end-plate. WE. have no evidence which could help in deciding this problem.

The paradoxical responses which this patien $\overrightarrow{\overline{\bar{\phi}}}$ showed to ephedrine, prostigmine, decamethonium? and "tensilon" suggest that in her case there ma六. be some hitherto unrecognized defect in the muscle fibre and/or its end-plate or membrane. We ca通 think of no better description for her condition thap " benign congenital myopathy with myasthenic features" while recognizing that we do not under? stand the essential nature of her disorder.

Although this patient, so far as we are aware shows features which are unique, there is no doub that other cases showing a resemblance to this clinical picture are seen from time to time. One of us (J. N. W.) in a previous communication (Waln్

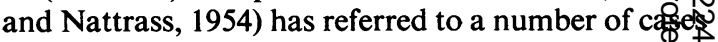
of " myasthenic myopathy". This term is probapl unsatisfactory, as it could be taken to refer to the irreversible muscular weakness and atrophy we may develop in the limb or ocular muscles of certai long-standing cases of myasthenia gravis. One of (J. A. S.) in a recent study of a large series of cheses of the latter condition has come to feel that stych changes occur in a not insignificant proportion of cases and may follow a recognizable pattern, paf ticularly in the limb muscles. However, the thres cases briefly referred to by Walton and Nattras (1954) were not of this type; rather, they wer: individuals with a long-standing weakness an atrophy of girdle and limb muscles who yet showef a somewhat phasic course and a definite, thoug sometimes temporary, response to ephedrine and/op prostigmine. Similar patients with a clinical picture like a combination of muscular dystrophy and: myasthenia gravis have been reported by Laruele and Massion-Verniory (1937), by Jezkova angु Sachs (1939) and by Hosotte (1951). Hosotte's case however, may have been one of true myasthenig gravis with eventual amyotrophy. In none of the cases mentioned by Walton and Nattrass did the condition begin so soon after birth as in the patient described in the present report. It is of considerab interest that one of these patients, shortly to be reported by Griffin, Nattrass, and Pask (1956), was given increasing doses of prostigmine with apparents improvement in the power of the limbs, but 
with eventual respiratory paralysis, necessitating management with intermittent positive-pressure respiration. He was subsequently subjected to thymectomy with dramatic improvement.

It must be concluded that there exist a number of obscure disorders falling into the borderland of both myopathy and myasthenia gravis, of which the present case is a striking example. We have at present, however, no information to indicate the the nature of the basic muscular defect in such individuals.

\section{Summary}

The case is reported of a woman who developed muscular weakness and hypotonia in the first year of life; she has shown subsequently persistent though non-progressive weakness, with moderate diffuse atrophy of the upper facial, trunk, and limb muscles. Her weakness has always become worse after exertion and she has had slight dysphagia but no diplopia.

Extensive metabolic, electrophysiological, and therapeutic experiments have revealed no defect in carbohydrate utilization or in potassium metabolism. She is more resistant to decamethonium iodide than the normal individual and shows improvement on ephedrine therapy but none following tensilon. Prostigmine produces definite improvement in muscular power, but if continued indefinitely in moderate dosage it appears to produce an increase in weakness, particularly of the respiratory muscles. A muscle biopsy revealed only slight, indefinite changes compatible with a myopathic disorder.
It is suggested that this condition falls into a borderland of myopathy and myasthenia and that it should be styled " benign congenital myopathy with myasthenic features". It was not possible to determine the nature of the biochemical or other defect in the muscle fibre and/or its end-plate or membrane which was responsible for this patient's condition.

We wish to thank Dr. E. A. Carmichael for permission to report this case and for his encouragement and advice. We are also grateful to Dr. J. N. Cumings, Dr. B. McArdle, Dr. W. A. Cobb, and Dr. P. A. Merton for permission to quote their findings. Fig. 1 was prepared in the Department of Photography, the National Hospital, Queen Square, Fig. 2 in the Gardiner Institute of Medicine, University of Glasgow.

\section{REFERENCES}

Batten, F. E. (1910). Quart. J. Med., 3, 313.

Churchill-Davidson, H. C., and Richardson, A. T. (1952). Journal of Neurology, Neurosurgery and Psychiatry, 15, 129.

Eaton, L. M. (1954). Neurology, 4, 245.

Griffin, S. G., Nattrass, F. J., and Pask, E. A. (1956). Lancet. In

the press.
Harvey, A. M., and Masland, R. L. (1941). Bull. Johns Hopk. Hosp., 68, 81.

Hosotte, A. (1951). Presse méd., 59, 1146.

Jezkova, S., and Sachs, A. (1939). Cas Lék. ces., 78, 1354.

Krabbe, K. H. (1946). Kongenit generaliseret muskelaplasi, 338 meeting of the Danish Neurol. Soc.; case reported again by Brandt S. (1950): Werdnig-Hoffmann's Infantile Progressive Muscular Atrophy, p. 264. Munksgaard, Copenhagen.

Muscular Atrophy, p. 64. Munksgaard, Copenhagen.
Laruelle, L., and Massion-Verniory, L. (1937). J. belge. Neurol., 37, 376.

McArdle, B. (1951). Clin. Sci., 10, 13.

Rowland, L. P. (1955). Neurology, 5, 612.

, Korengold, M.C., Jaffe, I. A., Berg, L., and Shy, G. M. (1955). Ibid., $5,89$.

Turner, J. W. A. (1940). Brain, 63, 163.

- (1949). Ibid., 72, 25.

Walton, J. N. (1956). Lancet, 1, 1023.

—, and Nattrass, F. J. (1954). Ibid., 77, 169. 